
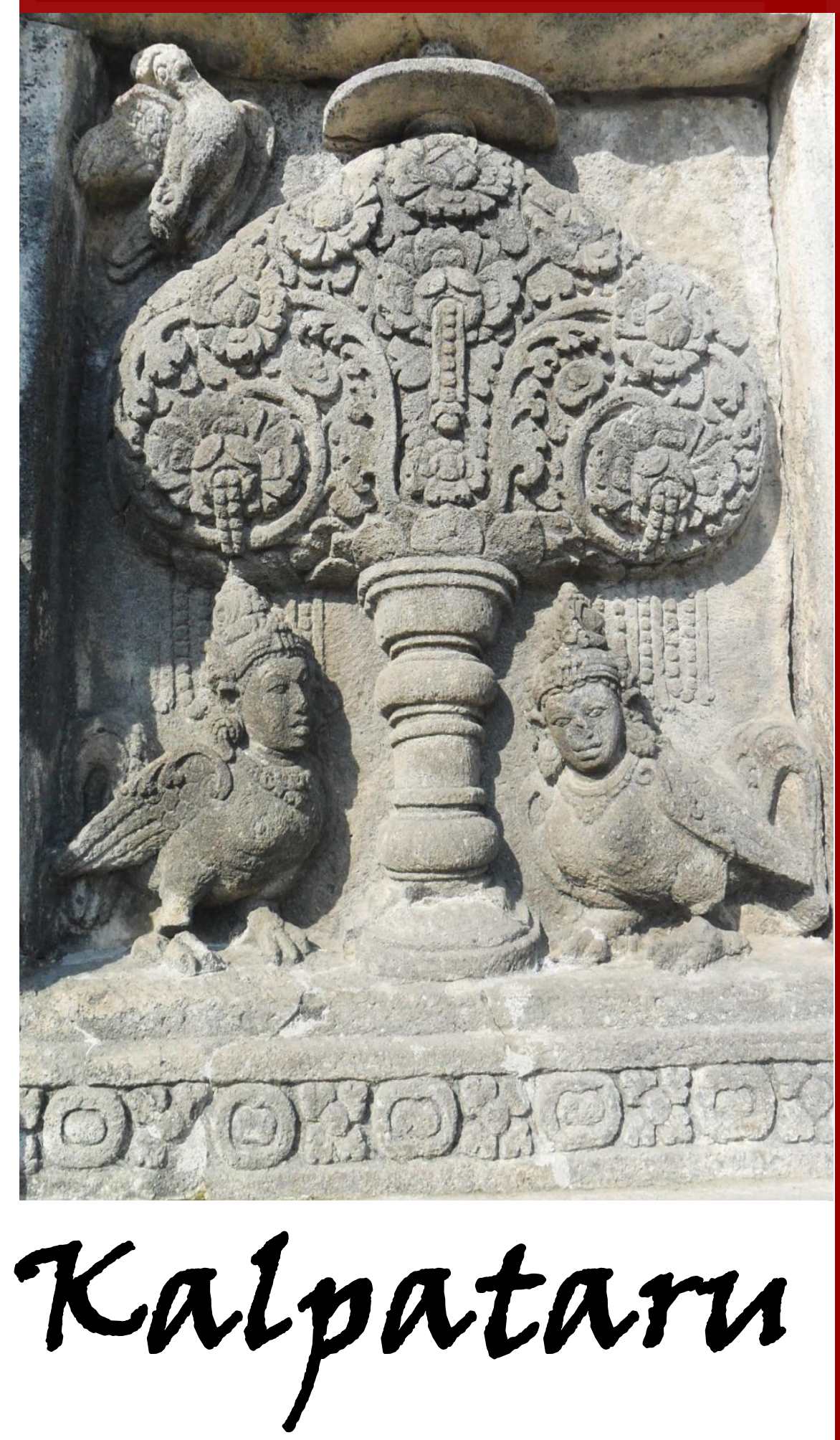

JURNAL SEJARAH DAN PEMBELAJARAN SEJARAH

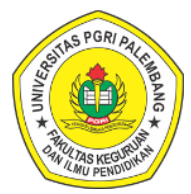

Program Studi Pendidikan Sejarah Jurusan Pendidikan IPS

Fakultas Keguruan dan IImu Pendidikan Universitas Persatuan Guru Republik Indonesia Palembang
Pengaruh Penerapan Model Project Based Learning Berbasis Video Vlog Dalam Proses Pembelajaran Sejarah Farena Adela, Nur Ahyani, Dina Sri Nindiati

Identifikasi Nilai Pedagogi Pada Pahatan Monolid Desa Jarakan Sebagai Sumber Pembelaran Sejarah Alzata Putra, Sukardi, Aan Suriadi

Nilai Sejarah Makam Puyang Ulak Laut di Pecah Pinggan Sebagai Sumber Pembelajaran Sejarah Berbasis Digital Dewi Cahya, Sukardi, Eva Dina Chairunisa

Pola Sebaran Permukiman di Kota Kayu Agung

I Made Lingga Wardana, Sukardi, Wandiyo

Peran Adam Malik Sebagai Ketua Sidang Majelis Umum PBB 1971 Rani Noviyanti

Pemanfaatan Foto dan Arsip Sebagai Sumber Pembelajaran Sejarah Riki Andi Saputro, Muhammad Fitri

Nilai-Nilai Sejarah Puyang Muara Rambang Sebagai Sumber Pelajaran Sejarah Lokal di SMA 01 Muarakuang Dwi Cahyati, Sukardi, Eva Dina Chairunisa

Pemikiran Abdul Mukti Ali Sebagai Sumber Pembelajaran Sejarah di SMA Patra Mandiri 1 Palembang Andika Merryanto Saputra, Aan Suriadi, Ahmad Zamhari

Perjuangan Hj. Rangkayo Rasuna Said Sebagai Pejuang Politik dan Pemikir Pergerakan Pada Masa Pra Kemerdekaan

Narani Agesti, Ageng Sanjaya

Nilai Sosial Religi Tradisi Manopeng Pada Masyarakat Banyiur Muhammad Fitri, Heri Susanto 
Kalpataru, Volume 7, Nomor 2, Desember 2021 (90-97)

\title{
IDENTIFIKASI NILAI PEDAGOGI PADA PAHATAN MONOLID DESA JARAKAN SEBAGAI SUMBER PEMBELARAN SEJARAH
}

\author{
Alzata Putra \\ Mahasiswa Program Studi Pendidikan Sejarah FKIP Universitas PGRI Palembang \\ Email: alzataeja@gmail.com \\ Sukardi \\ Dosen Program Studi Pendidikan Sejarah FKIP Universitas PGRI Palembang \\ Email: sukardisj@univpgri-palembang.ac.id \\ Aan Suriadi \\ Dosen Program Studi Pendidikan Sejarah FKIP Universitas PGRI Palembang \\ Email: aandesalega30@yahoo.com
}

\begin{abstract}
ABSTRAK
Pahatan adalah karya seni sekaligus sebuah peninggalan budaya dan sejarah di dalamnya juga terdapat nilai-nilai yang merupakan warisan dari para leluhur dituturkan dari generasi ke generasi, yang menjadikan sebuah peninggalan sejarah menjadi cerminan dari sebuah bukti penerapan pedagogi pada zaman prasejarah yang menguatkan bahwa eksistensi kehidupan perlu untuk diajarkan. Rumusan dari penelitian ini adalah nilai pedagogi apa saja yang terdapat pada batu berukir di Desa Jarakan? Adapun tujuan dari penelitian ini dalah untuk mengidentifikasi nilai pedagogi supaya bisa dimanfaatkan sebagai pembelajaran sejarah. Manfaat yang didapatkan bagi masyarakat setempat dapat menambah wawasan dan mengembangkan potensi wisata sejarah yang ada di dalamnya. Penelitian ini menggunakan metode penelitian deskriptif kualitatif dengan cara mengumpulkan sumber-sumber data secara sistematis dan sumber data yang mendalam dan berhubungan. Pengumpulan data dilakukan dengan cara survey lapangan, wawancara mendalam, pencatatan dokumen dan studi pustaka. Dalam penelitian kualitatif, ada empat teknik mencapai keabsahan data, yaitu: kredibilitas, transferabilitas, auditabilitas (dipendabilitas), konfirmabilitas dan triangulasi. Hasil dari penelitian ini dapat disimpulkan bahwa terdapat nilai pedagogi yang ada dalam pahatan Monolid di Desa Jarakan dan dapat diasumsikan bahwa nilainilai budaya dan seni serta keagamaan memiliki peranan penting dalam peradaban sejarah di desa tersebut.
\end{abstract}

Kata Kunci: Nilai Pedagogi, Pahatan Monolid

\section{A. PENDAHULUAN}

Sumatera Selatan yang merupakan salah satu provinsi di Indonesia memiliki 17 kabupaten/kota dan beragam budaya hasil dari sejarah panjang yang dilalui kota ini terdapat berbagai jenis peninggalan sejarah mulai dari masa prasejarah sampai pasca kemerdekaan. Keberagaman peninggalan sejarah yang diteliti menunjukan bahwa Sumatera Selatan kaya dengan kebudayaan ukiran. Sumatera Selatan sendiri secara geografis terletak di wilayah bagian Selatan pulau Sumatera memilikii kontur lahan datar, bergelombang dan pegunungan. Bagian Barat Provinsi Sumatera Selatan terdiri dari daratan bergelombang, pegunungan Bukit Barisan dengan puncak tertingginya adalah Gunung Dempo (Idris, 2017:167).

Sumatera Selatan juga terkenali memiliki kekayaan alam berupa, sungai, rawa, dan danau. Sungai-sungai besar di Sumatera Selatan bermata air di pegunungan Bukit Barisan, menalir ke daratan rendah dan bermuara di Selat Bangka. Ketika musim penghujan sungai-sungai di daratan rendah meluap dan membentuk genangan rawa-rawa di sisi kiri-kanan sungai. Kekayaan lahan basah tersebut membentuk kebudayaan manusia yang mendiami daratan rendah Sumatera Selatan 


\section{Kalpataru, Volume 7, Nomor 2, Desember 2021 (90-97)}

yang memiliki nilai kelokalan budaya yang unik, yaitu kebudayaan air Sumatera Selatan (Idris, 2017:167).

Di samping kebudayaan air, Sumatera Selatan juga menyimpan kebudayaan dataran tinggi yang tersebar luas mengikuti kontur Bukit Barisan wilayah ini sering disebut sebagai Pasemah, daerah Pasemah merupakan dataran tinggi seluas $80 \mathrm{~km}^{2}$. Daratan tinggi ini mempunyai bentuk memanjang dari arah Barat laut menuju Tenggara. Daratan tersebut merupakan bagian dari gugusan Bukit Barisan. Batas Geografis di sebelah Barat Daya adalah Gunung Dempo ( \pm 3159 mdpal) yang merupakan gunung tertinggi di Sumatera. Di sebelah Timur Laut adalah Gunung Belumai (1700 mdpala). Sungai yang mengalir di bawahnya adalah sungai Lematang, Selengsi, dan Endikat ketiganya menyatu dengan sungai Musi (Triwurjani, 2018:44).

Wilayah Pasemah berjarak $\pm 219 \mathrm{~km}$ dari Kota Palembang kearah Barat. Daerah ini meliputi 2 (dua) kabupaten, yaitu Kabupaten Lahat dan Kota Madyah Pagar Alam yang terletah di kaki Gunung Dempo (Triwurjani, 2018).

Kabupaten Empat Lawang diresmikan pada 20 April 2007. Kabupaten Empat Lawang yang sebelumnya bagian dari Kabupaten Lahat dan melakukan pemekaran. Walaupun demikian kebudayaan serta adat istiadat suku Pasemah masih melekat pada diri masyarakatnya termasuk sejarah dan kebudayaan megalit yang masih bisa di jumpai di salah satu daerah di Empat lawang.

Kabupaten Empat Lawang berada pada 3 0 25-4 0 15' Lintang Selatan dan 1020 37'-1030 45' Bujur Timur. Kabupaten Empat Lawang memiliki luas wilayah $2.256,44 \mathrm{~km}^{2}$ yang jenis lahannya sebagai berikut: tanah sawah terdiri dari: sawah irigasi, tadah hujan. Tanah kering terdiri dari emplasement, kebun, kolam; tanah hutan terdiri dari hutan lebat, belukar, hutang lindung; tanah perkebunan, yaitu tanah perkebunan negara/swasta, tanah umum. Tanah fasilitas umum yang terdiri dari tanah untuk lapangan olahraga, taman rekreasi, jalur hijau, pemakaman umum.

Di Kabupaten Empat Lawang tepatnya di Desa Jarakan yang masih merawat dan menyelamatkan satu ukiran batu pada Monolid peneliti meyakini bahwa ukiran pada batu tersebut mengandung nilai-nilai luhur yang dapat diwariskan pada generasi berikutnya. Batu berukir adalah tradisi yang berkembang dihampir semua wilayah Indonesia dan diwariskan secara turun temurun dari generasi kegerasi, sebaran batu berukir di Nusantara sangat luas dari Sabang sampai Merauke, banyak peneliti dan penulis berupaya dan mengangkat nilai-nilai yang terkandung pada ukiran atau realief batu. Sumatera Selatan kaya dengan relief batu seperti dalam tulisanya menyatakan bahwa (Sepriady, 2018) hasil tinggalan masyarakat Tegur Wangi berupa lukisan/pahatan dinding yang memiliki nilai kebudayaan yang sangat tinggi. Kemudian menyatakan adanya seni Lukis dan gores pada dinding batu di Pasemah, tampaknya merupakan symbol yang berkaitan dengan kepercayaan pendukungnya (Indriastuti, 2015:140).

Pada masa Hindu-Budha beberapa peneliti berusaha mengungkap nilai-nilai yang terkandung pada realief batu Hindu-Budha, salah satu peneliti yang melakukan penelitian tentang realif Hindu-Budha dan mengambil lokasi di candi Borobudur yang merupakan candi pada masa Hindu-Budha adalah dalam tulisanya menyatakan keberadaan realife jenisjenis hewan yang terdapat di dinding candi Borobudur secara implisit menunjukan beberapa jenis hewan telah dimanfaatkan untuk berbagai keperluan manusia sebelum abad keVIII yaitu jenis-jenis hewan budidaya (Idris, 2018:55).

Pada masa Islam terjadi perubahan pemakaian bahan untuk diukir apabila pada masa prasejarah sampai Hindu-Budha menggunakan batu sebagai tempat mengukir pada masa Islam tidak hanya menggunakan batu tapi ditambahkan jenis bahan kayu sebagai tempat mengukir/memahat, dalam tulisan (Ayuningtias, 2017:22). Corak seni ukir memet, kaligrafi, dan seni realif ukir kayu yang menggambarkan kisah-kisah para wali atau sunan di Jawa ketika sedang menyiarkan agama Islam.

Monolid Desa Jarakan berlokasi di Desa Jarakan, memiliki 6 pahatan yang yang terdapat 


\section{Kalpataru, Volume 7, Nomor 2, Desember 2021 (90-97)}

pada dinding batu perjalanan menuju Monolid ini dapat ditempuh dengan dua jenis kendaraan yaitu menggunakan motor dan mobil dengan kondisi jalan yang bertekstur tanah, sebagian masih tanah sebagian sudah beraspal perkiraan waktu 30 menit dari kantor camat Pendopo.

Dalam pahatan Monolid ini diperkirakan terkandung nilai-nilai pedagogi, Langeveld (1980) istilah pedagogi berarti pendidikan, yang lebih menekankan kepada praktek, menyangkut kegiatan mendidik, kegiatan membimbing anak, dengan mengambil dasar pemikiran menurut Langeveld pahatan Monolid memiliki peran penting dalam mempelajari cara kerja pedagogi pada masa prasejarah.

Kekayaan sejarah dan bukti bentuk budaya di salah satu wilayah Empat Lawang ini mendorong serta membuat peneliti ingin melakukan penelitian, untuk itu peneliti mengangkat objek ukiran di Desa Jarakan ke dalam penelitian yang berjudul "Identifikasi Nilai Pedagogi pada Pahatan Monolid Desa Jarakan Sebagai Sumber Pembelajaran Sejarah".

\section{B. METODE PENELITIAN}

Dalam penulisan skripsi ini peneliti menggunakan metode penelitian Deskriptif Kualitatif, yang menggunakan cara mengumpulkan sumber-sumber secara sistematis dan menggunakan sumber data secara mendalam. Penelitian Deskriptif Kualitatif diuraikan dengan kata-kata menurut responden, apa adanya sesuai dengan pertanyaan penelitiannya, kemudian dianalisis dengan kata-kata apa yang melatarbelakangi responden berperilaku (berpikir, berperasaan, dan bertindak) seperti itu tidak seperti lainnya, direduksi, ditriangulasi, disimpulkan (diberi makna oleh peneliti), dan diverifikasi (dikonsultasikan kembali kepada responden dan teman sejawat). Minimal ada 3 hal yang digambarkan dalam penelitian kualitatif, yaitu karakteristik pelaku, kegiatan, atau kejadiankejadian yang terjadi selama penelitian, dan keadaan lingkungan atau karakteristik tempat penelitian berlangsung (Sugiyono, 2017:205).

Metode penelitian ini merupakan cara yang digunakan oleh peneliti dalam mengumpulkan data penelitian. Seperti sudah dijelaskan, variasi dimaksud yaitu: angket, wawancara, pengamatan atau observasi, dan dokumentasi. Arikunto menjelaskan di dalam penulisan penelitian ini penulis menggunakan metode Deskriptif Kualitatif, mengumpulkan sumber-sumber secara sistematis dan menggunakan sumber data secara mendalam. Metode penelitian kualitatif dinamakan sebagai metode baru, karena popularitasnya belum lama, dinamakan postpositivistik karena berlandaskan pada filsafat postpositivisme. Metode ini disebut lebih bersifat seni (kurang berpola), karena disebut dengan metode interpretive karena data hasil penelitian lebih berkenaan dengan interpretasi terhadap data yang ditemukan dilapangan (Sugiyono, 2015:12-13).

Dengan berpedoman pada beberapa pengertian di atas memungkinkan menarik kesimpulan serta penjelasan bahwa metode Deskriptif Kualitatif adalah metode atau cara kerja dalam penelitian ini melakukan kajian mendalam pada suatu objek dan disimpulkan serta dijabarkan melalui tulisan kemudian disimpukan dan dikaitkan pada tujuan penelitian.

\section{HASIL DAN PEMBAHASAN Hasil Penelitian}

Penelitian dilaksanakan di Desa Jarakan Kabupaten Empat Lawang, waktu penelitian Minggu, 14 Februari 2021. Objek dari penelitian ini adalah sebuah batu besar atau sering disebut juga sebagai megalid yang memiliki sebuah ukiran (pahatan) terdapat 6 pahatan dalam megalid ini. Menimbang terdapatnya nilai pedagogi dalam situs ini dan mencerminkan sebuah cara nenek moyang menurunkan pengetahuannya ke generasi mudanya, dalam pengambilan data peneliti memilih menggunakan teknik wawancara dan observasi langsung kelapangan.

Observasi lapangan dilakukan mulai tanggal 14 Februari 2021, pada pukul 07.00 WIB tim peneliti berangkat ke lokasi Monolid menggunakan kendaraan roda dua dan sampai sekitar jam 08.00 WIB kemudian langsung melakukan observasi mengenai kontur letak mdpl dan flora maupun fauna di sekitar situs tidak lupa peneliti mengambil bukti foto. 


\section{Desa Jarakan dan Situs Monolid}

Secara administrasi Desa Jarakan termasuk ke dalam wilayah Kecamatan Pendopo, secara geografis pada bagian Utara Desa Jarakan berbatasan dengan Desa Umo Jati Kecamatan Lintang Kanan Kabupaten Empat Lawang, pada bagian Selatan berbatasan dengan Desa Bandar Agung, pada bagian Timur berbatasan dengan persawahan milik masyarakat, sebelah Barat berbatasan dengan perkebunan PT. ELAP.

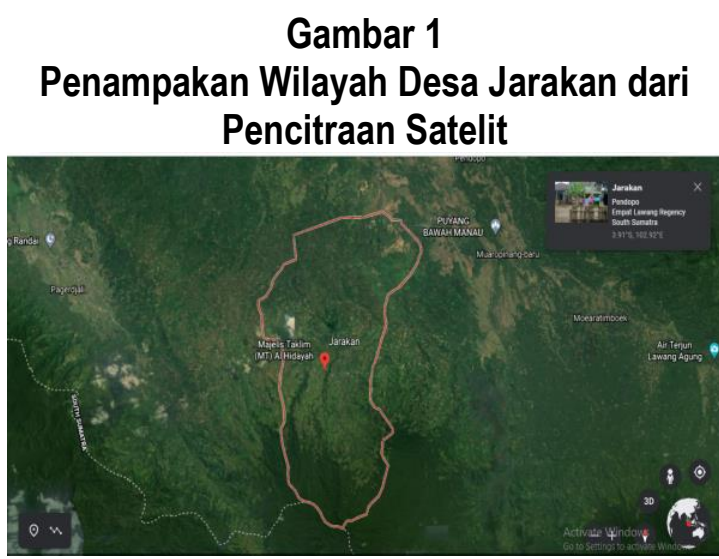

Sumber: Google Earth

Jarak Desa Jarakan dari pusat pemerintahan Kabupaten Empat Lawang kurang lebih $34,4 \mathrm{~km}$ jika menggunakan kendaraan roda dua (sepeda motor) ditempuh lebih kurang memakan waktu sekitar 1 jam, jika menggunakan kendaraan roda empat (mobil) akan memakan waktu sekitar 1 jam 30 menit. Jarak antara Desa Jarakan dengan Kota Palembang memiliki jarak lebih kurang $342,8 \mathrm{~km}$ dengan jarak tempuh lebih kurang 8-12 jam disesuaikan dengan kondisi kecepatan kendaraan serta jenis kendaraan.

\section{Pahatan Monolid Desa Jarakan}

Lokasi Monolid bukit Gadung jarak terdekat $21 \mathrm{~km}$ dari Desa Jarakan ditempuh \pm 57 menit dengan kendaraan roda empat atau roda dua atau berjalan kaki kuarang lebih \pm 5 jam ekologi Monolid bukit Gadung berada pada rangkaian Bukit Barisan, pada posisi mdpl, Monolid memiliki ketinggian kurang lebih \pm 8 meter dari permukaan tanah, monolid berada di tengah perkebunan rakyat dengan vegetasi dominan: kopi, karet, kelapa sawit, vegetasi besar disekitarnya berupa pohon kayu hutan dan kebun seperti: bambang, kapuk randu, durian, macang (putaran), mangga, jengkol, petai serta semak belukar. Kondisi tidak terawat pemanfaatan terakhir lokasi ini sebagai objek wisata lokal pada tahun 2020. Vauna: siamang, kera ekor panjang, dan aneka burung hal ini mengidentikasikan bahwa masih ada hutan primer di sekitar Monolid. Arah hadap Monolid kebukit Gadung dengan ketinggian bukit sebagai pusat konsentris 700-800 mdpl, kondisi bukit sendiri sudah mengalami kerusakan untuk pembukaan lahan kelapa sawit. Monolid berada $139^{\circ}$ arah Tenggara pada posisi $5.3^{\circ} 50^{\prime} 29^{\prime \prime} \mathrm{E}$ 102' $57^{\prime}$ '13'. Penelitian dilakukan pada pukul 09:58 kondisi cuaca berawan suhu $25^{\circ} \mathrm{C}$. Monolid diperkirakan cukup besar karena pada puncak permukaannya dilapisi tanah sehingga ditanami penduduk dengan kopi dan lada dengan peneduh johar kandang.

\section{Gambar 2 \\ Kenampakan Wilayah Situs Monolid Desa Jarakan dari Pencitraan Satelit}

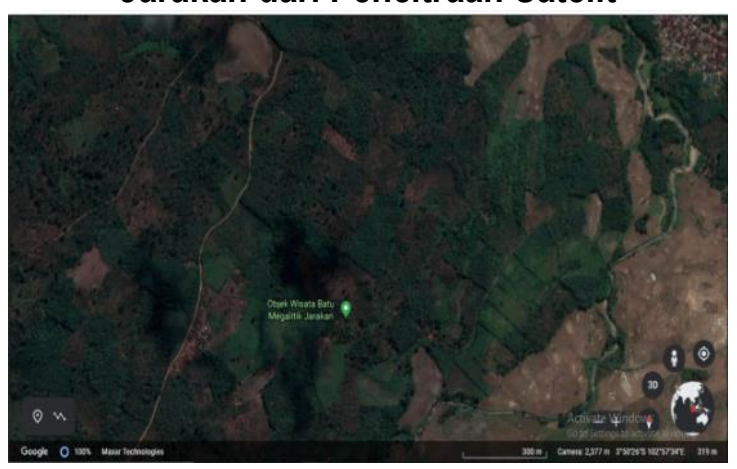

Sumber: Google Earth

Monolid utama lebih dominan dengan ukuran lebih besar, Monolid memiliki komposisi batuan pasir sehingga relatif rapuh, hal ini dibuktikan dengan temuan kolam-kolam kecil berbentuk lingkaran yang terbentuk akibat proses pelapukan batuan oleh air, Monolid kedua kurang lebih $\pm 5 \mathrm{~m}$ dari batuan pertama, menurut cerita penduduk sekitar pada batuan kedualah ditemukan ukiran. Monolid pertama memiliki panjang $\pm 30 \mathrm{~m}$ dengan ketinggian \pm 8 $\mathrm{m}$ Monolid kedua dan ketiga memiliki ukuran yang lebih kecil dengan ketinggian dari permukaan tanah $\pm 4 \mathrm{~m}$, panjang $\pm 20 \mathrm{~m}$. Kompisisi tetralit ditemukan tidak jauh dari Monolid kedua, dengan posisi vertikal berupa 
tiga jajaran batu yang disusun dengan jarak \pm 2 $3 \mathrm{~m}$.

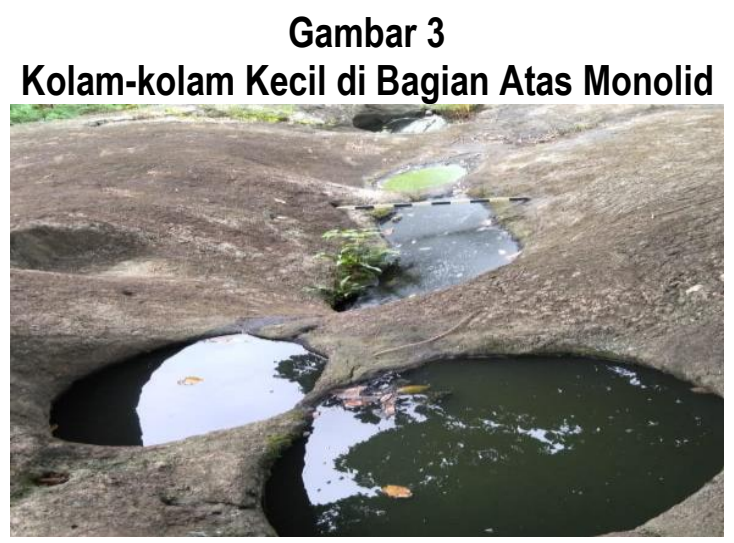

Sumber: Dokumentasi Peneliti

Pada Monolid ketiga ditemukan 6 kolam pada puncak Monolid dengan posisi memanjang beraturan, kolam terenda dengan kondisi tidak terawat ditumbuhi rerumputan dengan kondisi air yang kotor, kolam kedua nampaknya lebih dangkal dengan kondisi air kehijauan, kolam ketiga berada lebih tinggi dari kolam pertama dan kedua dengan panjang $\pm 2 \mathrm{~m}$, kolam keempat merupakan kolam tertinggi berupa dua buah kolam bundar berdiameter $1 \mathrm{~m}$ kondisinya relatif lebih bersih dengan kedalaman kolam mencapai $1 \mathrm{~m}$, kolam kelima berada pada sisi tebing mengarah ke Monolid kedua diameternya $1 \mathrm{~m}$.

Monolid ketiga ditutupi oleh vegetasi pohon karet yang cukup besar. Monolid kedua memiliki lobang kolam $\pm 28 \mathrm{~cm}$ yang berukuran lebih dari $50 \mathrm{~cm}$ dengan diameter besar $1,5 \mathrm{~m}$ dengan diameter terdalam $1 \mathrm{~m}$. Monolid ini memiliki panjang $\pm 30 \mathrm{~m}$ lebar $\pm 25 \mathrm{~m}$, tingginya \pm meter dari permikaan tanah, pada sisi Timur melandai dengan kemiringan $\pm 30^{\circ}$, sisi Barat memiliki kemiringan vertikal $80-90^{\circ}$ pada sisi datar arah Barat pada bidang dengan sudut kemiringan $90^{\circ}$ ditemukan pahatan pada batuan pasir yaitu sebagai berikut.

\section{Pahatan Pertama}

Berupa topeng tinggi $80 \times 45$ dengan teknik pahatan besi dengan ciri topeng mata bulat dipahat ke dalam berukuran besar, berbibir tebal kemudian dengan hidung dipahat lurus, rambut diukir dengan pahat lurus vertikal, topeng berukuran panjang $45 \mathrm{~cm}$, lebar dahi 40 $\mathrm{cm}$, lebar dagu $18 \mathrm{~cm}$, leher $6 \mathrm{~cm}$, mata kiri panjang $14 \mathrm{~cm}$ lebar $10 \mathrm{~cm}$, mata kanan panjang $14 \mathrm{~cm}$ lebar $11 \mathrm{~cm}$, bola mata kiri panjang $6 \mathrm{~cm}$ lebar $5 \mathrm{~cm}$, mata kanan panjang $8 \mathrm{~cm}$ lebar 6 $\mathrm{cm}$, alis kiri panjang $12 \mathrm{~cm}$ alis kanan panjang $13 \mathrm{~cm}$, panjang hidung $18 \mathrm{~cm}$, lebar $5 \mathrm{~cm}$, bibir panjang $13 \mathrm{~cm}$ bibir atas tebal $5 \mathrm{~cm}$, bibir bawah tebal $5 \mathrm{~cm}$, panjang rambut bagian atas $25 \mathrm{~cm}$ bagian bawah $10 \mathrm{~cm}$.

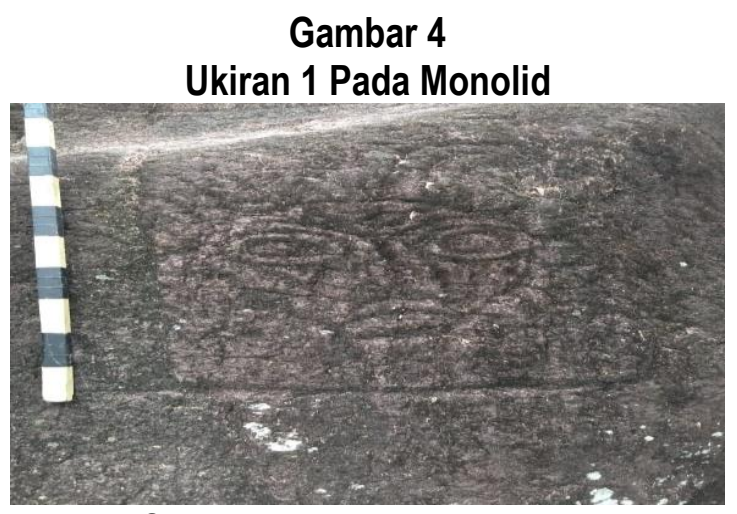

Sumber: Dokumentasi Peneliti

\section{Pahatan Kedua}

Berupa bunga dengan ukuran $88 \times 49$ $\mathrm{cm}$, dengan jumlah kelopak bunga empat kelopak yang lain tidak dapat diidentifikasi, kelopak bunga sebelah kanan panjang $20 \mathrm{~cm}$ lebar $10 \mathrm{~cm}$, kelopak bunga kedua panjang 29 $\mathrm{cm}$ lebar $8 \mathrm{~cm}$, pada bagian ujung $5 \mathrm{~cm}$, putik bunga berukuran $10 \times 10 \mathrm{~cm}$, malai bunga bagian atas panjang sembilan bagian bawah 3 $\mathrm{cm}$, yang atas telah rusak diperkirakan memiliki panjang $20 \mathrm{~cm}$ bagian bawah $5 \mathrm{~cm}$.

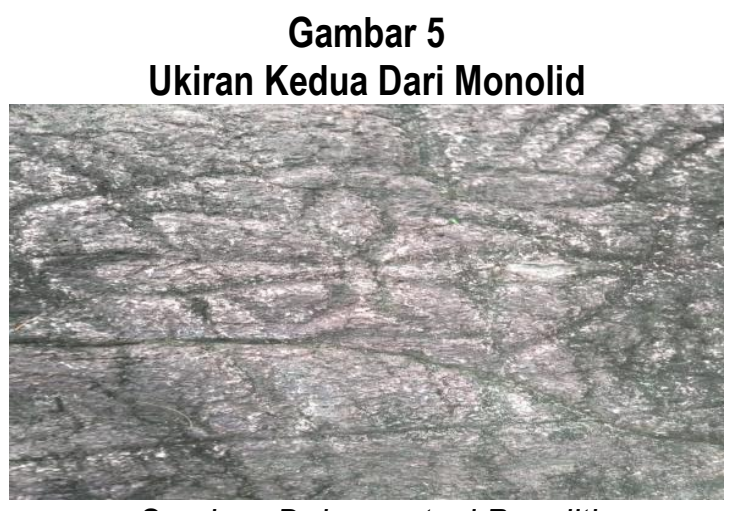

Sumber: Dokumentasi Peneliti

\section{Paharan Ketiga}

Berupa bunga dengan tiggi $72 \mathrm{~cm}$ lebar $70 \mathrm{~cm}$, ukiran bunga dipahat pada bidang yang berbentuk lingkaran dengan diameter $50 \mathrm{~cm}$, 


\section{Kalpataru, Volume 7, Nomor 2, Desember 2021 (90-97)}

bunga memiliki total panjang $13 \mathrm{~cm}$ dengan tebal 2,3 cm jumlah malai bunga 8 masingmasing tiga helai dikiri dan kanan 2 helai di atas dan di bawah, ukuran bunga, tinggi $36 \mathrm{~cm}$ akan tetapi dapat berukuran lebih mengingat bagian bawah telah rusak akibat tergerus air hujan. Lebar bunga $37 \mathrm{~cm}$, ketinggian dari permukaan tanah pada bagian atas $2,9 \mathrm{~m}$ pada bagian bawah $1,95 \mathrm{~m}$.

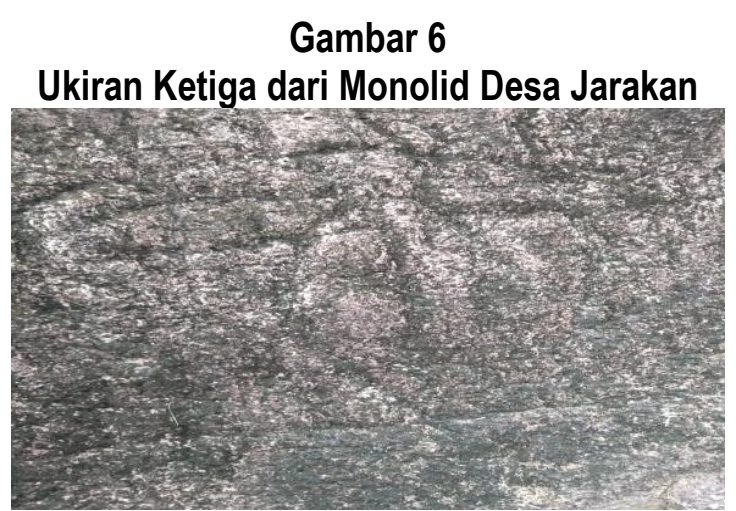

Sumber: Dokumentasi Peneliti

\section{Pahatan Keempat}

Ukiran topeng bagian bawah berada pada ketinggian $180 \mathrm{~cm}$ dari permukaan tanah lebar $185 \mathrm{~cm}$, tinggi $106 \mathrm{~cm}$, lebar jari $35 \mathrm{~cm}$, lebar dagu $15 \mathrm{~cm}$, panjang kepala $49 \mathrm{~cm}$, panjang leher $22 \mathrm{~cm}$, lebar leher $11 \mathrm{~cm}$. Pahatan diukir dengan permukaan kening menonjol, alis menonjol, mata pipih hidung dan dagu menonjol, lebar mata kanan $7 \mathrm{~cm}$ panjang 14,5 $\mathrm{cm}$, mata kiri panjang $13,5 \mathrm{~cm}$ lebar $8 \mathrm{~cm}$, hidung panjang $9,7 \mathrm{~cm}$, lebar bagian bawah 5,5 $\mathrm{cm}$ lebar bagian atas $2,5 \mathrm{~cm}$, bibir panajng 13 $\mathrm{cm}$ tebal bagian atas $3,7 \mathrm{~cm}$ bagian bawah 5,5 $\mathrm{cm}$ rambut atas panjang $33 \mathrm{~cm}$, rambut bawah $17 \mathrm{~cm}$.

\section{Gambar 7}

Ukiran Keempat Pada Monolid Desa Jarakan

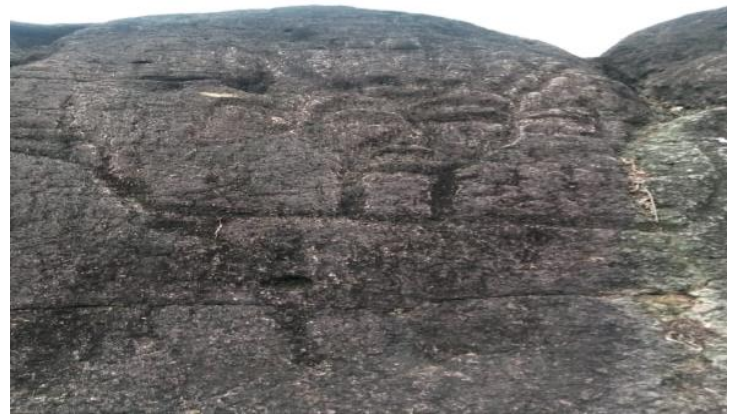

Sumber: Dokumentasi Peneliti

\section{Pahatan Kelima Berupa Bunga}

Dengan diameter $48 \mathrm{~cm}$, memiliki 5 kelopak bunga dengan panjang searah jarum jam di angkat $8,18 \mathrm{~cm}, 17 \mathrm{~cm}, 19 \mathrm{~cm}, 20 \mathrm{~cm}, 17$ $\mathrm{cm}$. Putik bunga sudah tidak terlihat, dibagian atas bunga terdapat 8 buah garis vertikal.

\section{Pahatan Keenam}

Berupa topeng panjang $77 \mathrm{~cm}$, tinggi 85 $\mathrm{cm}$, panjang kepala $40 \mathrm{~cm}$ lebar dahi $34 \mathrm{~cm}$ lebar dagu $14 \mathrm{~cm}$, panjang leher $16 \mathrm{~cm}$, lebar leher $10 \mathrm{~cm}$, tinggi rambut $18 \mathrm{~cm}$ bagian atas, rambut bagian samping $9 \mathrm{~cm}$. Pahatan lebih sederhana dengan penggambaran mata hanya berupa garis demikian juga bibir, bagian kiri kanan terdapat pahatan menyerupai tangan, lebar bahu $28 \mathrm{~cm}$, panjang tangan $20 \mathrm{~cm}$, panjanng jari-jari $13 \mathrm{~cm}$ (sama kiri kanan).

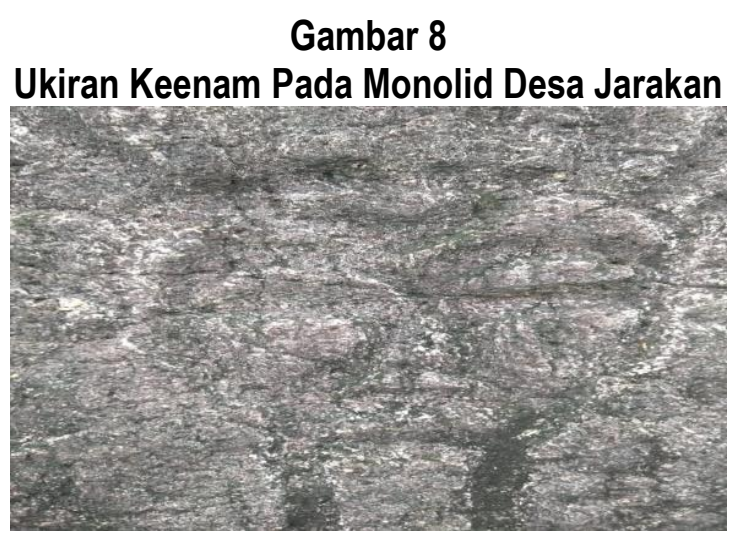

Sumber: Dokumentasi Peneliti

\section{Pembahasan \\ Nilai Pedagogi Pada Pahatan Monolid Desa Jarakan}

Dapat diidentifikasikan melalui goresan serta bentuk dari gambar pahatan yang tertuang dalam Monolid Desa Jarakan yang memiliki nilai kebudayaan yang tinggi serta makna tersendiri baik dalam bentuk bunga (kembang) mengartikan sebuah keindahan dan kesenian maupun dipahatan topeng yang mencerminkan sebuah keberadaan roh nenek moyang.

Pedagogi sendiri secara tradisional istilah pedagogi adalah seni mengajar. Langeveld (1980) pedagogi berarti pendidikan, yang lebih menekankan kepada praktek, menyangkut kegiatan mendidik, kegiatan membimbing anak. Dengan demikian dari sudut pandang temuan dilapangan memiliki beberapa ukiran topeng 


\section{Kalpataru, Volume 7, Nomor 2, Desember 2021 (90-97)}

yang disimpulkan adalah gambaran dari roh-roh nenek moyang, mencerminkan bahwa adanya penurunan pengetahuan keagamaan yang dilakukan pada generasi muda di zaman pembuatan ukiran ini.

Keterkandungan nilai pedagogi di dalamnya, mengasumsikan setiap pahatan yang terdapat di Monolid mengandung makna dan filosofi untuk mendidik serta mengajarkan kepada generasi mudanya dalam lingkup agama, budaya, dan berkehidupan sosial hal ini dikarenakan setiap corak yang ditampilkan dalam Monolid menggambarkan unsur-unsur yang telah disebutkan tadi sehingga penurunan ilmu yang dilakukan melalui media pahatan dengan keterbatasan pada masa yang telah diperkirakan oleh peneliti yaitu masa prasejarah. Di samping itu juga, hal ini disebabkan karena simbol-simbol dalam pahatan mewakili semua aspek yang telah disebutkan.

\section{Nilai Agama}

Dapat diliat dari penggambaran roh nenek moyang yang berupah topeng wajah mewakili keberadaan kehidupan lain yang berbeda dari kehidupan manusia tetapi masih tetap mempengaruhi kehidupan sosial dari penduduk itu sendiri diperkuat juga dengan keadaan sistem kepercayaan dari masa prasejarah yang menganut sistem Animisme dan Dinamisme dalam dua kepercayaan ini digambarkan lewat topeng sehingga terdapat gambaran keberadaan entitas kehidupan di luar kehidupan manusia.

\section{Nilai budaya}

Dilihat dari sisi budaya yang diajarkan pada generasi muda melalui pahatan Monoid ini peneliti berasumsi pada diturunkannya kemampuan seni dan kreatifitas tetapi masih dalam lingkup kebudayaan yang berkembang dikehidupan sosial masyarat pada masa Monolid ini dibuat karena terdapat corak bunga (kembang) disalah satu dari enam pahatan yang diteliti sehingga penurunan kemampuan mengekspresikan sebuah seni dan mewakili kebudayaan diajarkan lewat pahatan ini sekaligus budaya memahat batu atau membentuk batu yang tersebar di daratan Pasemah.

\section{Nilai pendidikan}

Mewakili mendidik dan pendidikan sekaligus juga mewakili pedagogi ini merupakan contoh yang sangat baik dikarenakan pahatan inilah bentuk dari pedagogi dan mendidik generasi muda agar tetap menjaga budaya dan melestarikan sistem kepercayaan yang diturunkan secara turun-temurun perwakilan ini dapat dilihat langsung pada letak dari pahatan yang diasumsikan peneliti terletak di tempat yang strategis dan tempat yang disucikan karena terdapat anak sungai dan di dataran tinggi yang merupakan tempat sering terjadi interaksi di sana.

Diperkuat juga dengan berbagai macam peradaban yang berkembang di sekitar sungai, dikaitkan dengan letak Moolid yang dekat dengan sungai seharusnya sungai tersebut adalah jalur transportasi yang pastinya sangat penting dan selalu dilalui oleh masyarakat, di sisi lain ini menjadi nilai tambah yang besar agar penyerapan penurunan pengetahuan menjadi lebih efektif karena mudahnya akses menuju Monolid.

\section{Relevansi Nilai Pedagogi pada Pahatan Monolid di Desa Jarakan Sebagai Materi Pembelajaran Sejarah}

Berdasarkan hasil wawancara dengan guru di SMA Bhakti Ibu 8 Palembang bernama Bapak Wahyu Ramadhani, S.Pd. materi pembelajaran sesuai dengan dengan Kompetensi Dasar (KD) dan Indikator Pencapaian Kompetensi (IPK) yang telah ditentukan dalam Kurikulum 2013 (K13). Setelah penentuan materi pembelajaran, maka dapat dikembangkan dalam kegiatan pembelajaran sejarah dengan judul "Identifikasi Nilai Pedagogi Pada Pahatan Monolid di Desa Jarakan" termasuk dalam Kompetensi Dasar (KD) 3.3. Menganalisis kehidupan manusia purba dan asal usul nenek moyang bangsa Indonesia (Melanosoid, Proto, dan Deutero Melayu) dengan uraian sebagai berikut:

\begin{tabular}{|l|l|}
\hline & Menganalisis kehidupan \\
3.3 & manusia purba dan asal usul \\
Kompetensi & nenek moyang bangsa \\
Dasar & Indonesia (Melanosoid, \\
& Proto, dan Deutero Melayu). \\
\hline
\end{tabular}




\begin{tabular}{|l|l|}
\hline $\begin{array}{l}\text { 3.3.1 Indikator } \\
\text { Pencapaian } \\
\text { Kompetensi }\end{array}$ & $\begin{array}{l}\text { Menjelaskan Identifikasi } \\
\text { Nilai Pedagogi pada } \\
\text { Jarakan. Monolid di Desa }\end{array}$ \\
\hline 3.3.1.1 Materi & $\begin{array}{l}\text { Identifikasi Nilai Pedagogi } \\
\text { Pada Pahatan Monolid di } \\
\text { Desa Jarakan. }\end{array}$ \\
\hline
\end{tabular}

Jadi materi tentang "Identifikasi Nilai Pedagogi pada Pahatan Monolid di Desa Jarakan" dapat menjadi sumber pembelajaran sejarah pada kelas $X$ di SMA Bhakti lbu 8 Palembang, dan dapat dikembangkan lagi karena bagian dari sejarah Indonesia masa praaksara agar siswa dapat memahami nilai pedagogi terhadap sejarah masa prakaksara

Dengan penjabaran Kompetensi Dasar dan Indikator Pencapaian Kompetensi di atas, maka materi dapat bermanfaat bagi siswa-siswi SMA Bhakti lbu 8 Palembang.

\section{SIMPULAN}

Berdasarkan hasil penelitian dan pembahasan yang penulis lakukan mengenai "Identifikasi Nilai Pedagogi pada Pahatan Monolid Desa Jarakan Sebagai Sumber Pembelaaran Sejarah" adapaun nilai pedagogi pada pahatan Monolid Desa Jarakan, di Desa Jarakan sendiri memiliki sebuah monumen Monolid yang di dalamnya terdapat 6 buah pahatan. Memiliki corak yang berbeda dan bentuk-bentuk yang unik di antaranya berbentuk kembang (bunga), kemudian berbentuk topeng, peneliti melebeli setiap pahatan dengan pahatan I, pahatan II, pahatan II, Pahatan IV, pahatan V, dan pahatan VI. Besaran ukuran yang berbeda beda tetapi perbedaannya tidak terlalu signifikan jika diukur perbedaaan ukuran sendiri hanya dalam lingkup centimeter terletak di satu batu yang sama dan berdempet dan tersusun sejajar. Arah hadap arca juga langsung menghadap ke gunung Dempo yang ada di Pagar Alam.

\section{DAFTAR PUSTAKA}

Ayuningtias, Putrid Pratiwi, K. K. (2017). "Analisis Perkembangan Motif Ukiran di Jepara Pada Abad Ke-16 Hingga Abad Ke-17". Kreasi , 22.

Idris, M. (2017). Serpihan Sejarah Kebudayaan Swarna Dwipa. Banyuasin: Excellent Publishing.

Idris, R. F. (2018). "Kisah Realife Fauna pada Candi Borobudur". Kalpataru. 44-56.

Indriastuti, K. (2015). "Seni Lukis dan Seni Gores Pada Megalit Pasemah Provinsi Sumatera Selatan". Siddhayatra. 140.

Sepriady, Jeki \& Muhamad Idris. (2018). Kesadaran Diskursif Manusia Prasejarah di Daratan Tinggi Basemah (Studi Analisis Megalit di Desa Tegur Wangi Kota Pagar Alam). Kalpataru. 29-40.

Sugiyono. (2015). Metode Penelitian Pendidikan Pendekatan Kuantitatif, Kualitatif, dan $R \& D$. Jakarta: Alfabeta.

Sugiyono. (2017). Metode Penelitian Kuantitatif, Kualitatif dan $R \& D$. Bandung: Alfabeta.

Triwurjani, R. (2018). Arca-arca Megalit Pasemah Sumatera Selatan. Jakarta: Yayasan Pustaka Obor Indonesia. 


\section{KETENTUAN PENULISAN ARTIKEL JURNAL KALPATARU}

1. Naskah berbahasa Indonesia yang disempurnakan bertemakan kesejarah yang meliputi hasil penelitian sejarah, pengajaran sejarah dan penelitian kebudayaan.

2. Naskah harus asli dan belum pernah dimuat dalam media lain. Naskah dapat berupa hasil penelitian/artikel kajian konseptual yang ditulis oleh perorangan dan atau kelompok.

3. Naskah ditulis dengan cara-cara yang sesuai dengan ketentuan penulisan artikel ilmiah menggunakan bahasa Indonesia yang baku, berupa ketikan, beserta soft file dalam CD-RW atau dengan mengirimkan email pada redaksi jurnal Kalpataru dengan alamat jurnalkalpatarusejarah@gmail.com, spasi tunggal, jenis huruf arial narrow ukuran 12, dengan panjang naskah antara 8-15 halaman pada kertas A4.

4. Artikel hasil penelitian memuat:

JUDUL

Nama Penulis

Abstrak

\section{: XXX (HURUF KAPITAL)}

: (disertai jabatan, institusi, dan email)

: (Bahasa Indonesia yang memuat 100-200 kata diikuti kata kunci, dengan jenis huruf arrial narrow dan ukuran huruf 11 serta dicetak miring). masalah penelitian, dan tujuan penelitian).

\section{B. METODE PENELITIAN}
: (memuat latar belakang masalah, tinjauan pustaka secara ringkas,
A. PENDAHULUAN

C. HASIL DAN PEMBAHASAN

D. SIMPULAN

: (berisi simpulan).

DAFTAR PUSTAKA : : (berisi pustaka yang dirujuk dalam uraian naskah).

5. Artikel Kajian Konseptual memuat:
JUDUL
Nama Penulis
Abstrak
: XXX (HURUF KAPITAL)
: (disertai jabatan, institusi, dan email)
: (Bahasa Indonesia yang memuat 100-200 kata diikuti kata kunci, dengan jenis huruf arrial narrow dan ukuran huruf 11 serta dicetak miring.
PENDAHULUAN
: (memuat latar belakang masalah, tinjauan pustaka secara ringkas, masalah penelitian, dan tujuan penelitian).
Sub Judul
: Sesuai dengan kebutuhan (tanpa numbering).
Simpulan
DAFTAR PUSTAKA
: (berisi simpulan dan saran).

6. Referensi sumber dalam teks artikel ditulis dengan menggunakan side note, contoh (Jalaludin, 1991:79); sementara penulisan daftar pustaka disusun dengan ketentuan. Nama pengarang. Tahun terbit. Judul (dicetak miring). Kota terbit: Nama Penerbit. Contoh: Koentjaraningrat. 2010. Manusia dan Kebudayaan di Indonesia. Jakarta: Djambatan. Daftar pustaka hanya memuat pustaka/sumber yang dirujuk dalam uraian dan disusun menurut abjad tanpa nomor urut.

7. Naskah yang dimuat akan disunting kembali oleh redaksi tanpa mengubah isinya.

8. Naskah yang ditolak (tidak bisa dimuat) akan dikirim kembali ke penulis dengan pemberitahuan tertulis dari redaksi atau melalui email.

9. Penulis yang naskahnya dimuat akan mendapat 1 (satu) majalah nomor yang bersangkutan.

10. Kontak person: Muhamad Idris (081271498618); Eva Dina Chairunisa (082281267851); Jeki Sepriady (085269261780). 